\title{
Identidad e identificación: investigación de campo como herramienta de aprendizaje en el diseño de marcas
}

\section{Identity and identification: field research as a learning tool in brand design}

\author{
Mgs. Carlos Enrique Nájera Galeas \\ Universidad Técnica de Ambato, Ecuador \\ Bertha Alejandra Paredes Calderón \\ Escuela Superior Politécnica de Chimborazo, Ecuador
}

Autor para correspondencia: ce.najera@uta.edu.ec; bparedes@espoch.edu.ec Fecha de recepción: 24 de Junio de 2017 - Fecha de aceptación: 15 de Septiembre de 2017

Resumen: Las marcas como escenarios que representan el conjunto de atributos y valores de un producto, empresa o ciudad, son consecuencia de un estudio exhaustivo de contextos reales. La investigación de campo como método permite la intervención del observador en un entorno físico, partiendo de la visita al emplazamiento, para luego observar el lugar y fotografiarlo, esquematizar las imágenes y finalmente esbozar conceptos. Este proceso involucra la etnografía como herramienta que le permite al diseñador especular menos sobre la realidad. Su resultado consolida un conjunto de acciones que fortalecen la imagen positiva del producto, cuya deducción es la "MARCA", mejora su percepción a nivel local e internacional obteniendo una ventaja competitiva frente a otros. El diseño y creación de una Marca constituye una forma de reforzar la realización de un nuevo sistema de valores expresado en el reconocimiento de bienes o servicios característicos del producto, donde el diseñador cumple un papel fundamental en la representación de acciones durante la investigación. Finalmente es importante fortalecer la enseñanza del diseño de marcas basadas en métodos y técnicas que permitan una representación gráfica fruto de una investigación previa que consolida los procesos metodológicos propios del diseñador.

Palabras Clave: identidad; etnografía; investigación de campo; marca; símbolo; valor de marca

\begin{abstract}
Brands as scenarios that represent the set of attributes and values of a product, company or city, are the result of an exhaustive study of real contexts. Field research as a method allows the observer to intervene in a physical environment, starting from the site visit, then observing the place and photographing it, schematizing the images and finally outlining concepts. This process involves ethnography as a tool that allows the designer to speculate less about reality. Its result consolidates a set of actions that strengthen the positive image of the product, whose deduction is the "BRAND", improves its perception at local and international level obtaining a competitive advantage over others. The design and creation of a Brand is a way of reinforcing the realization of a new value system expressed in the recognition of goods or services characteristic of the product, where the designer plays a fundamental role in the representation of actions during the investigation. Finally, it is important to strengthen the teaching of the design of brands based on methods and techniques that allow a graphic representation resulting from a previous research that consolidates the methodological processes of the designer.
\end{abstract}

Key words: identity; ethnography; field research; brand; symbol; brand value 


\section{Introducción}

El aprendizaje del diseño es un proceso interdisciplinario, en la cual el diseñador debe identificar problemas, establecer y proponer soluciones, en base a una metodología, que se proyecta en plataformas complejas y específicas que no tan solo es útil en el proceso de diseño sino también se convierten en herramientas de desarrollo del mismo. El docente como actor principal dentro del proceso de enseñanza aprendizaje garantiza la utilización de métodos holísticos que le permitan al estudiante (diseñador) cumplir con sus objetivos de una manera más realista acorde a un contexto representado por un conjunto de valores reales. La marca con su intenso poder comunicativo es el medio ideal para representarlas.

La investigación de campo y la etnografía, brindan una visión integral del consumidor, pues supera la ficción de ver el ser humano como un ente que toma decisiones en solitario, y más bien entenderlo como un ser social y cultural, influenciado por una gran cantidad de factores, como sus sistemas simbólicos, creencias religiosas, su identidad, por ritos y mitos, entre otros (Badot, C., \& Cova, D. Filser, 2009).

El empleo de la investigación de campo y la etnografía, objetualiza la investigación al crear herramientas gráficas a través de disciplinas propias de la comunicación visual como la semiótica, el branding y la antropología, que consienten el diseño de identificadores, cuyo principal valor sea la representación de sus atributos reales plasmados en una marca gráfica, cuya base de estudio y análisis sean las pizarras gráficas, mismas que le permiten a la marca, identificar e integrar todas las actividades productivas que realiza la empresa, institución o lugar, incentivando un sentido de pertenencia y conservando la estructura de valores y creencias. Este sistema simbólico creado a partir del uso de la investigación de campo garantiza en cierta forma la representación de los mismos en sus públicos.

\section{Desarrollo del artículo}

\section{Aporte Científico o Académico}

Los antecedentes de la investigación de campo, se encuentran donde los pensadores e investigadores, aplicaron de manera consciente e intencionada algunas formas o modos de recabar información, tratarla, analizarla, interpretarla y aplicarla sobre algún fenómeno social. (Muñoz, 2002, p.13).

La investigación de campo, esencial en cualquier proyecto de intervención física en un entorno humano, exige que el diseñador se ciña a las limitaciones específicas de una ubicación. A su vez el contexto local determinará la forma o el uso del lenguaje (Lupton, 2011, p. 50)

Lupton, E. (2011). Determina como puntos relevantes: la visita al emplazamiento, donde refiere que la mejor forma de reflexionar sobre un lugar es visitarlo; observar el lugar y fotografiarlo para evaluar críticamente el grafismo del entorno y cualquier otro signo o señal; esquematizar las imágenes donde se simplifica las fotografías trazando bocetos sobre ellas y finalmente esbozar conceptos para explorar las relaciones del contexto. 
La investigación etnográfica trata de explicar y comprender la actuación del sujeto en el contexto, en este método se utilizan con fuerza la observación y el registro como técnica que permite la elaboración de la etnografía. A partir de este registro se buscan los indicadores o parámetros que aparecen durante el relato de los hechos. (Pérez, García, Nocedo y García Inza, 2009, p.91)

Reyes (2013) menciona que la etnografía ha dado grandes aportes conceptuales. Gracias a esta sabemos cómo alrededor de las marcas y en general del consumo se pueden crear comunidades, de la experiencia de los consumidores en los canales de comercialización retail, del uso de las marcas en la vida cotidiana de las personas, del proceso de decisión del consumidor y de cómo estos crean asociaciones o dan significados a las marcas y productos.

Es importante vincular a la técnica etnográfica con la observación cuyo objetivo es conseguir y describir a los grupos sociales y escenas culturales. Las descripciones detallan situaciones, eventos, personas, interacciones y comportamientos que son observables y captan el sentido que las personas dan a sus actos, a sus ideas, y al mundo que les rodea.

Para Amir (2010). A través de la etnografía se logra una visión integral de las marcas, que consiste en explorar 3 dimensiones:

a. Símbolos: palabras, imágenes, signos u objetos que tienen un significado particular dentro de una cultura.

b. Rituales y héroes: rituales son actividades colectivas esenciales para una cultura, mientras que héroes son personajes vivos o muertos, reales o hipotéticos, que poseen características muy apreciadas y por lo tanto representan un modelo de comportamiento.

c. Valores: son el núcleo de la cultura, un conjunto de sentimientos y comportamientos asumidos como naturales. Dimensiones que responden a una micro, meso y macro etnografía respectivamente.

El "hacer branding puede entenderse como, construir valor de marca mediante la comunicación efectiva de los atributos que se quieran trasladar a la mente de los receptores" (Fernández y Cavia, 2011). Fernández es más explícito al referirse al Branding como un proceso comunicativo, en el cual están inmersos todos sus actores: un emisor (empresa, institución, lugar, persona) y sus receptores, comprendidos como públicos objetivos o segmentos de mercado; y el mensaje representado por la marca en todas sus aplicaciones y canales, determinados en el plan de medios; un actor imprescindible en el proceso es el codificador, que es el encargado de realizar la marca.

La identidad de marca puede definirse como un conjunto de asociaciones mentales en torno a la proposición de valor de la marca que la empresa, institución o lugar desea suscitar en la mente del usuario cuando éste entra en contacto con la misma a través de cualquier vía.

Algunos autores distinguen una diferencia entre los tipos de identidad que al parecer de la teoría conjugan en un solo hecho. Es así que la identidad corporativa se ha concebido como algo interno y controlable por la organización, que se proyecta de modos concretos con el objetivo de 
generar una impresión (imagen) específica en los diversos stakeholders (por ejemplo trabajadores, consumidores o inversionistas) con los que se relaciona la empresa. (Currás, 2010, p.7)

Para Chajet, y Shachtman, (1998). La identidad visual hace referencia a la representación gráfica de la identidad corporativa, en forma de símbolos y señales como marcas, logotipos, decoración, estilo corporativo, vestuario del personal, etc. La identidad organizacional (término más usado en el área de comportamiento organizacional) Albert y Whetten, (1985) "lo definen como aquello que los miembros perciben como lo central, distintivo y duradero en la organización".

Es imperativo distinguir la diferencia entre identidad de marca e imagen de marca: el primer concepto alude a las representaciones mentales deseadas por la empresa, mientras que el segundo se refiere a aquellas que efectivamente surgen en la mente del cliente; se trata, por tanto, de dos conceptos íntimamente relacionados entre sí, porque se refieren al mismo objeto, pero, a su vez, claramente diferenciados: la identidad se ubica en el interior de la empresa, materializándose en objetivos y planes; la imagen, en cambio, se sitúa en el exterior, en la mente de las personas (Beristain, 2002, p 36).

Como parte de la investigación es importante dilucidar las dimensiones de la marca, ya que de esta dependerá el uso del método y la técnica relacionados con la investigación. Según Aaker (1996) "estas son las dimensiones que conforman la identidad de la marca” (p. 82).

- Marca como producto: asociaciones relacionadas con la clase de producto, atributos, calidad, ocasiones de uso, usuarios o país o región oferente.

- Marca como organización: asociaciones relativas a la organización que ofrece el producto (cultura organizativa, valores, planes, etc.).

- Marca como persona: asociaciones relacionadas con la personalidad de la marca (cualidades propias de las personas que son trasladables a los productos: serio, divertido, informal, competente, etc.).

- Marca como símbolo: imagen visual de la marca que representa la esencia de la misma.

Beristain (2002). "Estas dimensiones representan un espectro de posibilidades al servicio del estratega de marcas, que puede ser aplicado con mayor o menor intensidad según las circunstancias" (p. 38).

La marca y su relación semiótica para López (2002) son expuestas como, "la marca actual es un paradigma de identificación y personalidad, un reservorio simbólico del cual se alimenta el producto; el rasgo supremo de la marca es su irreductible naturaleza comunicativa". Desde el enfoque de López, el signo de la marca es connotar; su objeto, competir. Asumiendo dichos conceptos, se reconoce entonces la naturaleza semiótica de la marca y su funcionalidad como productora de significados, con lo que se exalta la definición de "significante".

"El signo o símbolo es cualquier cosa perceptible (palabra, señal, letra, frase, etc.) que representa a algo, a su objeto referente" (Pierce, 1985). 
Ahora bien, ese signo o símbolo crea otro signo en la mente del individuo que lo interpreta: el interpretante, que se corresponde con el pensamiento subjetivo que interpreta a un significado. El proceso de significación de Pierce (1985) difiere del tradicional modelo lingüístico significante/significado, aportado por la escuela estructuralista de Saussure (1964), incluyendo un tercer elemento, el interpretante, que deja espacio a la interpretación individual del significado. Para Pierce (1985), la relación entre un signo y un objeto tiene un sentido preciso para un individuo, vinculándose a afectos, recuerdos y experiencias, gracias al elemento interpretante. En el ámbito de la organización, el interpretante se corresponderá con la noción de imagen corporativa (Christensen y Askegaard, 2001).

Así también Berdichewky en Acevedo (2013) cita: "la antropología es el estudio concreto de los grupos humanos, tanto del punto de vista biológico - poblaciones genéticas - como del punto de vista social - sociedades, comunidades - también se preocupa de la interacción de estos dos aspectos - lo biológico y lo socio-cultural- se caracteriza por métodos comparativos para dicho propósito y por el intento de obtener una visión holística, global, tanto de los aspectos interrelacionados de cada comunidad como de la especie humana en su totalidad.

En conclusión los elementos teóricos planteados por uno y/o diferentes autores fundamentan el conocimiento y aclaran la importancia de cada una de las disciplinas y su aporte en la enseñanza de la marca así como también definir su vínculo en materia gráfica.

\section{Metodología}

La gran mayoría de las investigaciones llevadas a cabo por los diseñadores son más cualitativas que cuantitativas, lo que implica que el diseñador tiene que desarrollar un método que le permita categorizar y analizar la información recopilada con el fin de descubrir y entender como es el panorama general y transmitir los mensajes y los hallazgos más importantes. (Milton y Rodgers, 2013, p.19)

Al registrar la investigación de campo en el tema, claramente se habla de una investigación cualitativa, fundamentada en la etnografía, que admite el uso de la observación no participativa y la intervención multidisciplinaria de la semiótica para la creación de iconos representativos configurados en la mente del público objetivo, sustentando la creación y aplicación del branding.

Ya dentro del proceso inicialmente se establece la población o grupo social/ cultural motivo de estudio, dicha población son: clientes, consumidores, turistas etc... Que bajo el debido proceso serán parte de un cálculo de la muestra cuyo principal objetivo es determinar la situación actual y los factores de relevancia del lugar o institución a investigar.

Para la aplicación de la metodología se propone la creación de "la marca ciudad de Baños de Agua Santa" motivo de desarrollo de la investigación. Se obtiene una población total de 36018 , el cálculo de la muestra determina un total de 380 personas y la técnica de muestreo aleatoria simple. La mencionada muestra contribuye a recolección de información basada en un contexto social participativo. 
Tabla I

Población y muestra

\begin{tabular}{|c|c|c|c|}
\hline POBLACIÓN & MUESTRA & DETALLE & $\begin{array}{l}\text { TÉCNICA DE } \\
\text { MUESTREO }\end{array}$ \\
\hline $\mathrm{N}=36018$ & $P(1-P)$ & Confianza $=95 \%$ & Muestreo \\
\hline $\begin{array}{l}\text { Hombres y mujeres } \\
\text { residentes, turistas } \\
\text { nacionales y extran- } \\
\text { jeros de } 15 \text { a } 64 \\
\text { años }\end{array}$ & $\begin{array}{l}\frac{E^{2}}{Z^{2}}+\frac{P(1-P)}{N} \\
n=380 \text { personas }\end{array}$ & $\begin{array}{l}e=5 \%=0,05 \\
Z=1,96 \\
P=0,5 \\
1-p=0,5 \\
N=36018\end{array}$ & $\begin{array}{l}\text { aleatorio } \\
\text { simple }\end{array}$ \\
\hline
\end{tabular}

Fuente: Carlos Nájera y Bertha Paredes

La parte primordial de la metodología basa su esfuerzo en el estudio del entorno y creación de dos pizarras gráficas donde se precisan elementos simbólicos (semiótica), que luego de ser analizados aportan en la creación de la marca. Es así que la práctica permite establecer al moodboard donde se conoce al grupo cultural y recoge una visión global del ámbito social estudiado desde distintos puntos de vista: un punto de vista interno y una perspectiva externa. Dichas perspectivas identifican aspectos como sus atractivos naturales e históricos, comercio y arte, estos datos se conceptualizan y agrupan en categorías, que mediante un proceso de manipulación y organización de los mismos, conectan los resultados obtenidos a un cuerpo más grande de conocimiento los interpreta y los da sentido.

El Cooldboard finalmente genera categorías conceptuales y descubre regularidades y asociaciones entre los fenómenos observados que permiten establecer modelos y posibles teorías explicativas de la realidad objeto de estudio, su enfoque evidencia principalmente las acciones o actividades de la población en estudio.

Este valioso proceso de identificación de factores relevantes sean gráficos, o contextuales le permiten al diseñador especular menos y trabajar sobre una base sólida de información donde, la aplicación final denota un proceso de abstracción resultado del análisis de las pizarras gráficas.

\section{Resultados y discusión}

El resultado de la investigación de campo, plasmada en las pizarras gráficas disciernen los principales actores y factores relevantes que por medio de la semiótica y el diseño gráfico se convertirán en la marca encargada de identificar.

La siguiente figura evidencia las pizarras gráficas fruto de la investigación, de la ciudad de Baños de Agua Santa, identificando a partir de ellas un escenario social, a través de la investigación de campo como principal estrategia para obtener información, genera categorías conceptuales y descubre regularidades y asociaciones entre los fenómenos observados que permiten establecer modelos y posibles teorías explicativas de la realidad objeto de estudio. 


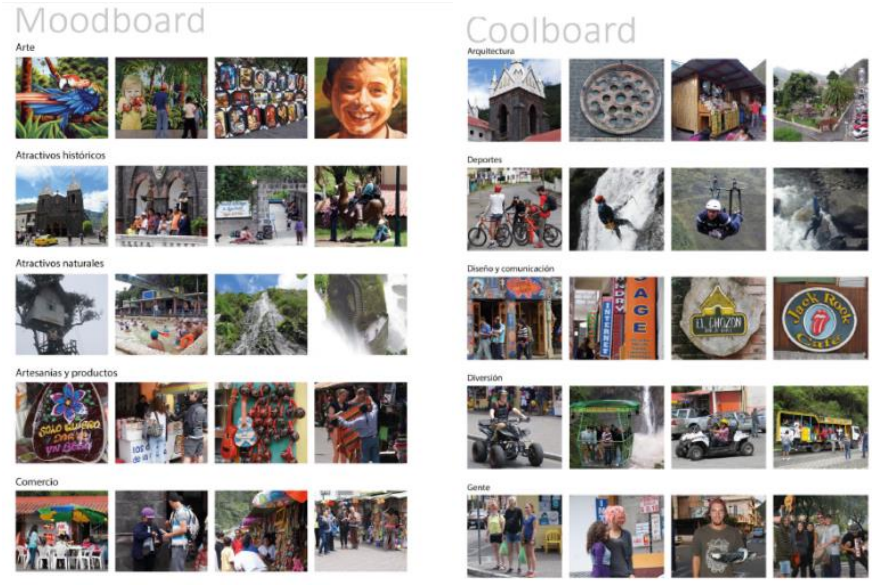

Figura 1: Pizarras gráficas Baños de Agua Santa Fuente: Carlos Nájera y Bertha Paredes

El estudio semiótico exhibe que la ciudad de Baños de Agua Santa es poseedora de iconos gráficos que la diferencian de otras urbes, dichos elementos se evidencian a través de pizarras gráficas y se les da el tratamiento gráfico indispensable para la formación de la marca que junto con el valores como: Naturaleza y Cultura cimentan la creación de la misma. Siendo entonces uno de los principales elementos que componen la marca ciudad de Baños el icono encontrado en la fachada principal de la Basílica de la Virgen de Baños de Agua Santa, la cual erige sus cimientos el 11 de febrero de 1904 y ve concluida su labor 40 años más tarde, obra impulsada debido al entusiasmo y valentía del sacerdote Tomas Cornelio Halflants de origen Belga.

Esta obra monumental de tinte gótico exhibe sobre su entrada principal una gran ventana de forma circular que tiene una vidriera calada y adornada con diferentes colores, cuyos soportes internos se disponen generalmente de forma radial, conocida como rosetón, que se utilizó en la arquitectura románica y en la gótica, siendo el encargado de crear ambientes deslumbradores, divinos y religiosos, capaces de emular la entrada al cielo y de enseñar con sus pinturas las historias de las Sagradas Escrituras a los fieles en las catedrales, pero también los rosetones avisan sobre la naturaleza del edificio. Los rosetones además de contribuir a la iluminación del interior de las catedrales, poseen una fuerte carga simbólica, debido a su parecido a una rosa se la atribuye un simbolismo Mariano, pero también puede remitir a Cristo como asociación a los rayos del sol. Las rosas representan a María, "rosa sin espinas", ya que fue concebida sin el pecado original.
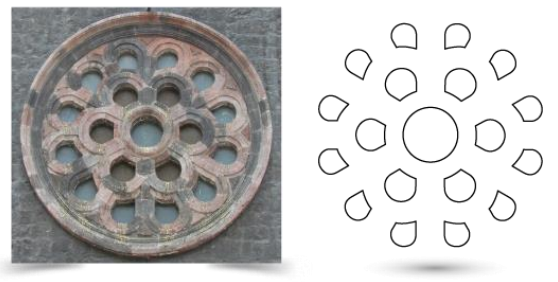

Figura 2: Rosetón

Fuente: Carlos Nájera y Bertha Paredes 
El enfoque de trabajo se basa principalmente en un estudio de entorno natural y cultural, se optó por sumar a la propuesta de diseño un icono que represente el lado innato de la ciudad, visto a través, de la inclusión del girasol como estampa de naturaleza, que ha ornado las cabezas de emperadores romanos, de los reyes de la Europa oriental y de Asia, y que ha sido utilizado en la iconografía cristiana en relación con los más santos de entre los santos. Esta planta, procedente del continente americano, además de ser un excelente adorno, tiene utilidades medicinales y cosméticas, sus semillas son una especie de aperitivo.

Esta flor está llena de luz, energía y vitalidad, tal vez por su vinculación con el astro más potente del cosmos, que simboliza tradicionalmente a Dios, a lo Divino, a esa trascendencia que nos mantiene vivos con su luz y calor, es también un referente de la geometría natural al exponer en su estructura una perfecta armonía entre simétrica y cromática, su belleza es tal que ni siquiera Van Gogh y Picasso pudieron resistir la tentación de pintar en grandes lienzos estas hermosas flores.
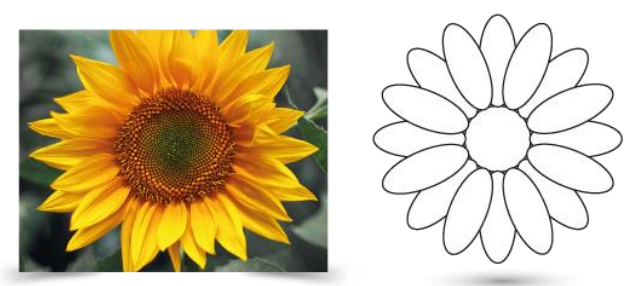

Figura 3: Girasol

Fuente: Carlos Nájera y Bertha Paredes

Estos iconos significativos, tanto, de la arquitectura gótica, como innatos de la urbe, se obtuvieron con fines pertinentes a la creación de la marca-ciudad de Baños a través de la abstracción de tipo geométrico de su estructura característica, a partir de la etnografía, la observación y documentación fotográfica como proceso de construcción gráfica.

Es oportuno mencionar que el estudio sensato de los rasgos característicos de los elementos presentes en el entorno, a través de la investigación de campo y la etnografía, aportan un amplio abanico de posibilidades en la consecución y cimentación de marcas alusivas a localidades con fines pertinentes a la promoción y difusión de sus atributos tanto naturales cono culturales.

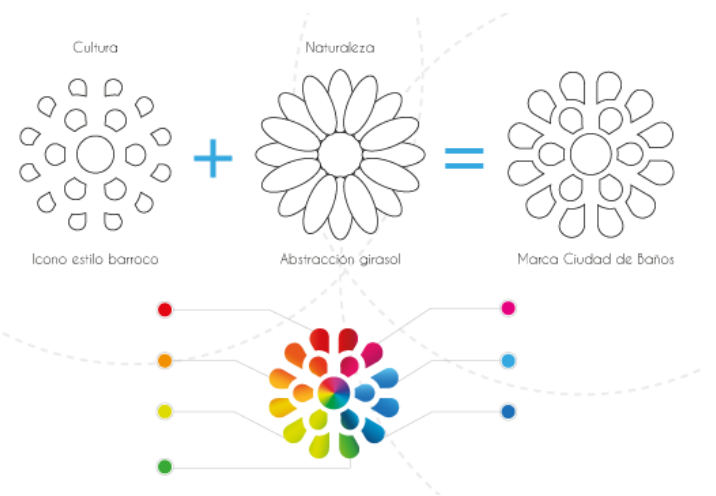

Figura 4: Propuesta Marca-Ciudad Baños

Fuente: Bertha Paredes y Carlos Nájera 
De esta forma la propuesta de marca presenta valores que identifican al entorno social y cultural, garantizando el cumplimiento de sus funciones. Finalmente cabe mencionar que la implementación de la marca no es objeto de estudio, por lo tanto no es motivo de investigación.

\section{Conclusiones}

La enseñanza del diseño de marcas basadas en métodos y técnicas que consientan una representación gráfica fruto de una investigación previa, ayuda a consolidar procesos metodológicos propios del diseñador.

Los métodos de investigación cualitativos, ofrecen una amplia gama de técnicas que admitan el análisis de la información, cuyo resultado son piezas graficas con elementos que representan los valores identitarios y simbólicos.

El empleo de la semiótica contribuye a la comprensión del contexto humano y la necesidad de comunicarse simbólicamente.

El empleo de disciplinas relacionadas directamente al contexto, comportamiento y estudio del hombre, facilita la creación de la marca y sus valores intrínsecos.

La Marca-Ciudad Baños ha incorporado, algunos de los factores representativos naturales, culturales y sociales juzgados bajo las perspectivas de la etnografía, la investigación de campo y la observación. Factores eco-turísticos, culturales y hasta religiosos dieron origen a un proceso y una marca con importantes repercusiones.

\section{Bibliografía}

Acevedo, O. (2007). El producto con denominación de origen: Lectura de la identidad del hacer de un territorio. The international Committee for the Conservation of the Industrial Heritage (TICCIH).CEDODAL. Buenos Aires, Argentina.

Aaker, D. A. (1996). Measuring brand equity across products and markets. California management review, 38(3), 102-120.

Albert, S., \& Whetten, D. A. (1985). Organizational identity. Research in organizational behavior.

Badot, C., \& Cova, D. Filser.,(2009). The contribution of Ethnology to research in consumer and shopper behavior: towards Ethnomarketing [La contribución de la etnología en las investigaciones del consumidor y el comportamiento del comprador: todo lo relacionado a etnomarketing]. Recherche et Applicatons en Marketing, 8(29), 93-1.

Beristain Oñederra, J. J. (2002). Marcas de distribución: del labeling al branding. Distribución y consumo, (64), 35-45.

Chajet, C., \& Shachtman, T. (1998). Image by design. McGraw-Hill, New York, NY 
Currás Pérez, R. (2010). Identidad e imagen corporativas: revisión conceptual e interrelación. Teoría y Praxis, (7).

Fernández Cavia, J. (2011). Ciudades, regiones y países como marcas: luces y sombras del place branding. Manual de comunicación turística, 103-113.

López, M. (2002). "La semiótica mete la cuchara: De cómo la Semiótica salió del aula y entró al salón del directorio". Revista Razón y Palabra, (28), 1-13. Santiago, Chile. Recuperado de: http://www.razonypalabra.org.mx/anteriores/n28/mlopez.html.

Lupton, E. (2011). Graphic design thinking: Beyond brainstorming. Princeton Architectural Press. P. 50

Milton, A., \& Rodgers, P. (2013). Métodos de investigación para el diseño de producto. Blume.

Muñoz, V. (2002). Técnicas de investigación de campo I. guía de autoaprendizaje. México.

Pérez Rodríguez, G., García Batista, Gilberto., Nocedo de León, I. R. M. A., \& García Inza, M. L. (2009). Metodología de la investigación educacional.

Reyes Reina, D. (2013). La etnografía en los estudios de marca: una revisión bibliográfica. Pensamiento \& Gestión, (34). 